\title{
Nickel-catalyzed Amination of Aryl Thioethers: A Combined Synthetic and Mechanistic Study
}

\section{Journal Article}

Author(s):

Bismuto, Alessandro (1); Delcaillau, Tristan; Müller, Patrick; Morandi, Bill

Publication date:

2020-04-17

Permanent link:

https://doi.org/10.3929/ethz-b-000405732

Rights / license:

In Copyright - Non-Commercial Use Permitted

Originally published in:

ACS Catalysis 10(8), https://doi.org/10.1021/acscatal.0c00393

Funding acknowledgement:

184658 - Catalytic synthesis of unprotected amines and heterocycles (SNF) 
This document is the Accepted Manuscript version of a Published Work that appeared in final form in ACS Catalysis, copyright (C) American Chemical Society after peer review and technical editing by the publisher. To access the final edited and published work see https://doi.org/10.1021/acscatal.0c00393

\title{
Nickel-catalyzed Amination of Aryl Thioethers:
}

\section{A Combined Synthetic and Mechanistic Study}

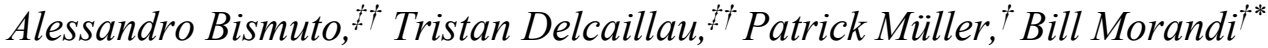 \\ 'Laboratorium für Organische Chemie ETH Zürich Vladimir-Prelog-Weg 3, HCI, 8093 Zürich, \\ Switzerland
}

KEYWORDS organonickel chemistry; Buchwald-Hartwig Amination; Reaction Mechanism; kinetics; thioethers

ABSTRACT Herein, we report a nickel-dcype complex for the catalytic Buchwald-Hartwig amination of aryl thioethers. The protocol shows broad applicability with a variety of different functional groups tolerated under the catalytic conditions. Extensive organometallic and kinetic studies support a nickel(0)-nickel(II) pathway for this transformation and revealed the oxidative addition complex as the resting state of the catalytic cycle. All the isolated intermediates have proven to be catalytically and kinetically competent catalysts for this transformation. The fleeting transmetallation intermediate has been successfully synthesized through an alternative synthetic organometallic pathway at lower temperature, allowing for in situ NMR-study of the $\mathrm{C}-\mathrm{N}$ bond reductive elimination step. This study addresses key factors governing the mechanism of nickel-catalyzed Buchwald-Hartwig amination process, thus improving the understanding of this important class of reactions. 
This document is the Accepted Manuscript version of a Published Work that appeared in final form in ACS Catalysis, copyright (C) American Chemical Society after peer review and technical editing by the publisher. To access the final edited and published work see https://doi.org/10.1021/acscatal.0c00393

\section{INTRODUCTION}

The last two decades have seen palladium dominating the cross-coupling scene through the activation and functionalization of several $\mathrm{C}-\mathrm{X}$ bonds. ${ }^{1 \mathrm{a}-\mathrm{c}}$ Among those, one of the most relevant is the Buchwald-Hartwig cross-coupling reaction which provides access to $\mathrm{C}-\mathrm{N}$ moiety starting from aryl halides or $p s e u d o$-halides. ${ }^{2 \mathrm{a}-\mathrm{d}}$ The high abundance of the aniline motif in agrochemicals, ${ }^{3}$ natural products and pharmaceuticals ${ }^{4 a, b}$ has kept motivating researchers to tackle the natural limit of functional group tolerance of this reaction. ${ }^{5 a, b}$ This, has allowed outstanding examples of late-stage functionalization as well as industrial-scale applications. ${ }^{\text {aa,b }}$ The advances in the synthetic utility were combined with thorough investigation of the mechanism of this transformation, thus allowing the development of new catalysts with improved reactivity. ${ }^{7 a, b}$

Preliminary studies using monoligated palladium-phosphine complexes suggested a pathway whereby the Buchwald-Hartwig amination reaction is proposed to start with the activation of an aryl halide bond through an oxidative addition step to form a palladium(II) species (Scheme 1, A). ${ }^{8 a, b}$ The latter was found to be in equilibrium with a dimeric species which has been fully characterized and identified as a resting state of the catalytic cycle. Subsequent transmetallation, favored by the addition of a base, led to a functionalized complex whereby reductive elimination released the product and regenerated the metal catalyst. Unfortunately, formation of an imine byproduct through a $\beta$-hydride elimination of the $\operatorname{Pd}\left(\mathrm{NR}^{1} \mathrm{R}^{2}\right) \mathrm{Ar}$ complex was often observed. ${ }^{9}$ The coordination mode of the ligand was found to play a crucial role in influencing the formation of the imine by-product with bidentate phosphines preventing this competing pathway, thus, enhancing catalytic activity. ${ }^{10 a-c}$ Since these findings, different ligands have been developed and 
This document is the Accepted Manuscript version of a Published Work that appeared in final form in ACS Catalysis, copyright (C) American Chemical Society after peer review and technical editing by the publisher. To access the final edited and published work see https://doi.org/10.1021/acscatal.0c00393

the isolation of many relevant intermediates has led to a near complete understanding of all the mechanistic nuances governing this transformation. ${ }^{11 \mathrm{a}-\mathrm{d}}$

Increasing concerns regarding sustainability, as well as the potential to uncover complementary reactivity, have driven researchers to seek for alternatives to precious transition metal catalysts. ${ }^{12 a, b}$ In this context, nickel-catalysis has received increasing interest in the field of cross-coupling chemistry. ${ }^{13 a-d}$ However, the availability of different stable oxidation states has often hampered mechanistic studies of Ni-catalyzed reactions. ${ }^{14 a-g}$ In particular, for crosscoupling reactions, the $\mathrm{Ni}(0)-\mathrm{Ni}(\mathrm{II})$ or $\mathrm{Ni}(\mathrm{I})-\mathrm{Ni}(\mathrm{III})$ pathways are often proposed. To date, it is not clear whether the latter simply represents a deactivation pathway or if those may interchange in cooperative fashion. ${ }^{15 \mathrm{a}-\mathrm{d}}$ For this reason, while the mechanism of palladium-catalyzed Buchwald-Hartwig amination has been extensively studied, the analogous process employing nickel is comparatively underexplored. ${ }^{16 \mathrm{a}-\mathrm{g}}$

Preliminary work has been reported by Hartwig and co-workers for a nickel-BINAP complex that is competent for the amination of aryl chlorides. Both stoichiometric and kinetic investigation were necessary to shed light on the possible mechanistic pathway. ${ }^{17}$ Notably, oxidative addition studies at a nickel center are usually limited by the availability of nickel(0) precursors (Scheme 1, B). As previously shown, formation of a dimeric nickel (I) species was observed when reacting the nickel precursor and the aryl chloride. Moreover, this species was later shown to be a decomposition product rather than a competent catalyst. However, upon tweaking of the reaction conditions, it was possible to isolate the oxidative addition product BINAP-Ni(Ar)Cl which was found to be competent in catalysis. ${ }^{17}$ A combination of detailed NMR and kinetic analysis led to the identification of the turnover limiting step as well as 
This document is the Accepted Manuscript version of a Published Work that appeared in final form in ACS Catalysis, copyright (C) American Chemical Society after peer review and technical editing by the publisher. To access the final edited and published work see https://doi.org/10.1021/acscatal.0c00393

possible deactivation products. The reaction is proposed to start with a turnover-limiting oxidative addition of the aryl chloride to form a Ni(II) species. Transmetallation and subsequent reductive elimination then releases the product and regenerates the metal catalyst. Both the oxidative addition and the transmetallation steps generate decomposition products which have hampered the isolation of other proposed intermediates of the cycle. Furthermore, the difficult access to $\operatorname{ArNi}\left(\mathrm{NR}_{2}\right)$ complexes and their rapid decomposition has limited the possibility to gather information on the reductive elimination step. Since this pioneering work, other nickel systems have been reported for the Buchwald-Hartwig amination reaction. ${ }^{16 a-g}$ However, the ambiguity of the oxidation states of the system, and the development of alternative pathways to prevent detrimental decomposition of the catalysts still remains an important challenge.

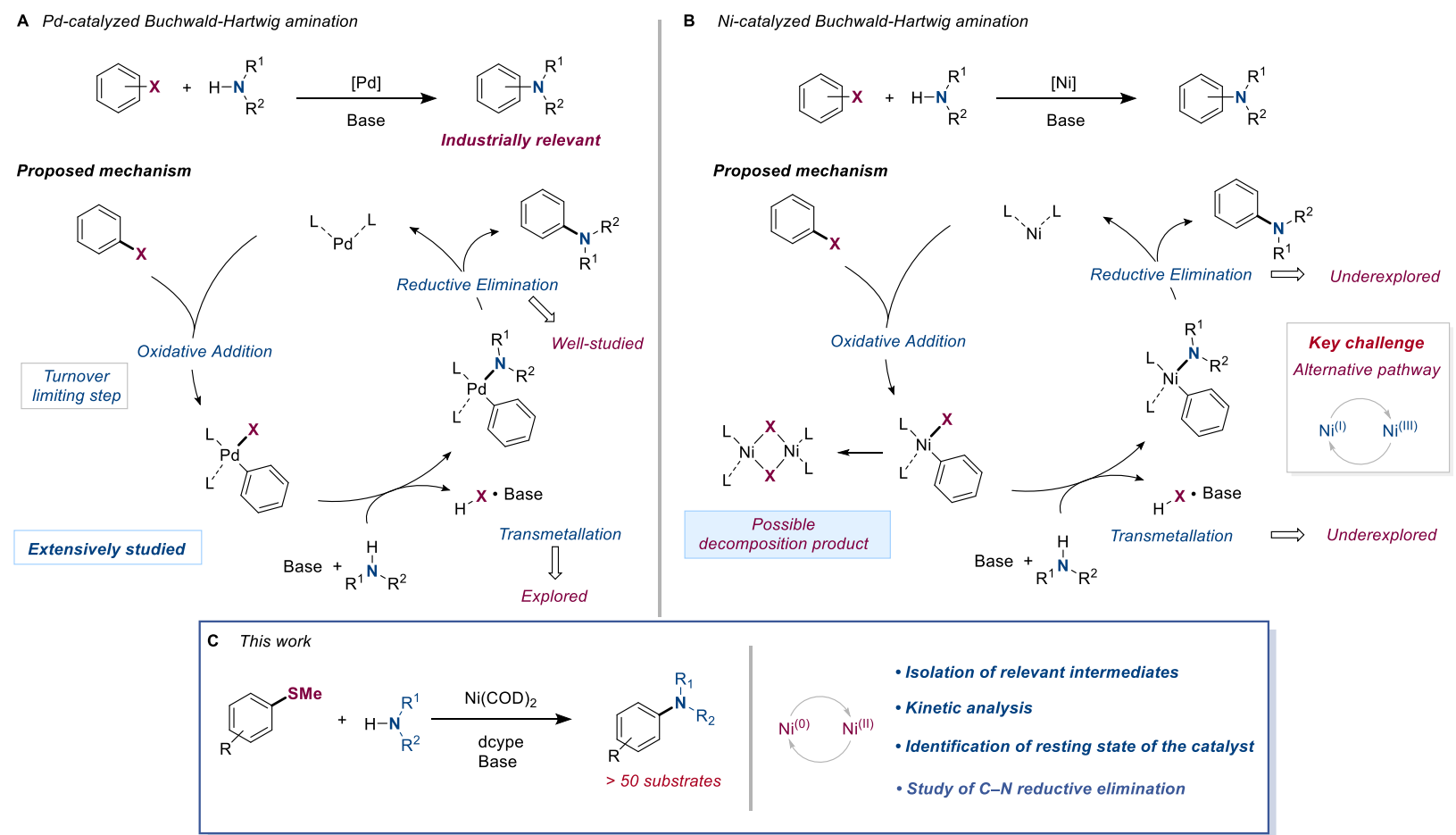

Scheme 1. Context of the work. 
This document is the Accepted Manuscript version of a Published Work that appeared in final form in ACS Catalysis, copyright (C) American Chemical Society after peer review and technical editing by the publisher. To access the final edited and published work see https://doi.org/10.1021/acscatal.0c00393

Inspired by work from Yorimitsu on the Pd-catalyzed Buchwald-Hartwig amination of thioethers, ${ }^{18 \mathrm{a}-\mathrm{c}}$ we have recently become interested in the activation of thioethers using both palladium and nickel catalysts, particularly within the context of a single bond metathesis paradigm. ${ }^{19 a, b}$ Thioethers have recently garnered attention as alternatives to halides in cross coupling reactions, providing new approaches to synthesize and derivatize complex synthetic intermediates. ${ }^{20 \mathrm{a}-\mathrm{f}}$ The lack of previous reports for a nickel-catalyzed Buchwald-Hartwig amination of thioethers motivated us to probe whether this base metal could serve as an alternative to the previously reported Pd system (Scheme 1, C). ${ }^{18-\mathrm{c}}$ We envisaged that exploiting the thioether group as an electrophile in the Buchwald-Hartwig reaction, could: (1) enable us to take advantage of the intrinsic higher stability and directing group ability of thioethers, when compared to traditional electrophiles (e.g. $\mathrm{Cl}, \mathrm{Br}){ }^{20 \mathrm{~b}, \mathrm{f}}(2)$ lead to a cleaner reaction profile thus enabling in-depth organometallic and kinetic studies, potentially revealing some critical mechanistic information about Ni catalysis.

In this work, we present a broadly applicable Ni-catalyzed amination reaction of aryl thioethers. Besides the synthetic studies of this new reaction, we also report detailed kinetic and organometallic experiments which support a Ni(0)-Ni(II) catalytic cycle. A highlight of this work is the synthesis and isolation of an unstable transmetallation complex, enabling a unique and detailed spectroscopic study of the $\mathrm{C}-\mathrm{N}$ reductive elimination step at a well-defined $\mathrm{Ni}(\mathrm{II})$ center.

\section{Result and Discussion}


This document is the Accepted Manuscript version of a Published Work that appeared in final form in ACS Catalysis, copyright (C) American Chemical Society after peer review and technical editing by the publisher. To access the final edited and published work see https://doi.org/10.1021/acscatal.0c00393

Evaluation of the catalytic system. We began our investigation using $\mathrm{Ni}(\mathrm{COD})_{2}$ as precatalyst, thioanisole and morpholine as benchmark substrates. Initial evaluation of different ligands such as monodentate phosphines $\left.\left(\mathrm{PPh}_{3} \text { and } \mathrm{PCy}\right)_{3}\right)$ led to the recovery of starting materials (see SI, table 1). We then evaluated different NHC ligands (IPr and SIPr) which showed no reactivity, confirming previous results reported by Yorimitsu and co-workers (a combination of $\mathrm{NiBr}_{2}$ diglyme and $\mathrm{IPr} \cdot \mathrm{HCl}$ was tested). ${ }^{18 \mathrm{a}}$ The first hit came with the use of dppe as ligand with formation of the expected product in $32 \%$ yield. We next analyzed the reactivity of several other bidentate phosphine ligands, and highly electron-rich ones emerged as the best systems for this reaction. Indeed, using dcypm and dcype led to the formation of the desired product in around $50 \%$ yield. The dcype/ $\mathrm{Ni}$ combination has been previously shown by Itami to be highly efficient for the oxidative addition of $\mathrm{C}-\mathrm{O}$ bonds in $\mathrm{C}-\mathrm{H} / \mathrm{C}-\mathrm{O}$ biaryl coupling of 1,3azoles and aryl pivalates. ${ }^{21}$ Interestingly, a slight excess of dcype with respect to $\mathrm{Ni}(\mathrm{COD})_{2}$ increased drastically the yield of the reaction to $95 \%$.

Table 1. Optimization of conditions. ${ }^{a}$
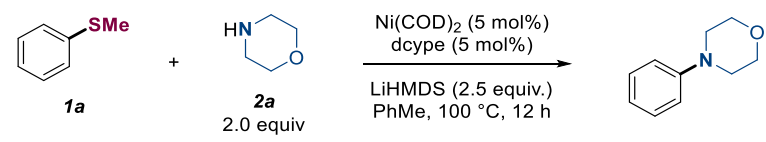

\begin{tabular}{ccc}
\hline Entry & Deviation from standard conditions & Yield [\%] ${ }^{\mathbf{b}}$ \\
\hline 1 & None & 51 \\
2 & L1 instead of L3 & 7 \\
3 & L2 instead of L3 & 0 \\
4 & L4 instead of L3 & 32 \\
5 & L5 instead of L3 & 48 \\
6 & L6 instead of L3
\end{tabular}


This document is the Accepted Manuscript version of a Published Work that appeared in final form in ACS Catalysis, copyright (C) American Chemical Society after peer review and technical editing by the publisher. To access the final edited and published work see https://doi.org/10.1021/acscatal.0c00393

$6 \mathrm{~mol} \% \mathrm{~L} 3$ instead of $5 \mathrm{~mol} \%$

95

8

KHMDS instead of LiHMDS

10

9

tBuOK instead of LiHMDS

0

10

1,4-Dioxane instead of $\mathrm{PhMe}$

traces
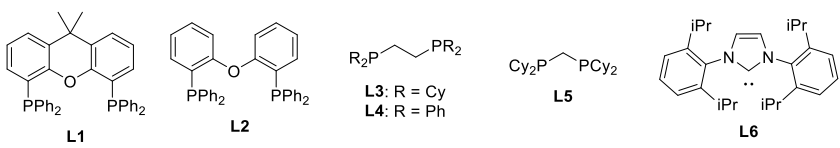

${ }^{\mathrm{a}} \mathbf{1 a}(0.2 \mathrm{mmol}), \mathbf{2 a}$ (1 equiv.), $\mathrm{Ni}(\mathrm{COD})_{2}(5 \mathrm{~mol} \%), \mathrm{PhMe}, 100{ }^{\circ} \mathrm{C}, 12 \mathrm{~h} .{ }^{\mathrm{b}} \mathrm{GC}$ yields using $n$ dodecane as internal standard.

Scope of Ni-catalyzed amination of thioethers. We next explored the substrate scope, with a particular focus on the functional group tolerance of this novel nickel-catalyzed amination methodology (Table 2). A wide range of thioanisole derivatives worked efficiently under those conditions. Indeed, electron-neutral (3aa, 3ab, 3ac \& 3ad), electron-rich (3ae, 3af, 3ag, 3ah \& 3ai), and electron-poor (3ak) arenes were tolerated providing the desired products in good to excellent yield. This methodology also proved to be highly efficient in the presence of a bicyclic compound 3aj.

Table 2. Substrate scope of thioanisoles with morpholine. ${ }^{a}$ 
This document is the Accepted Manuscript version of a Published Work that appeared in final form in ACS Catalysis, copyright (C) American Chemical Society after peer review and technical editing by the publisher. To access the final edited and published work see https://doi.org/10.1021/acscatal.0c00393

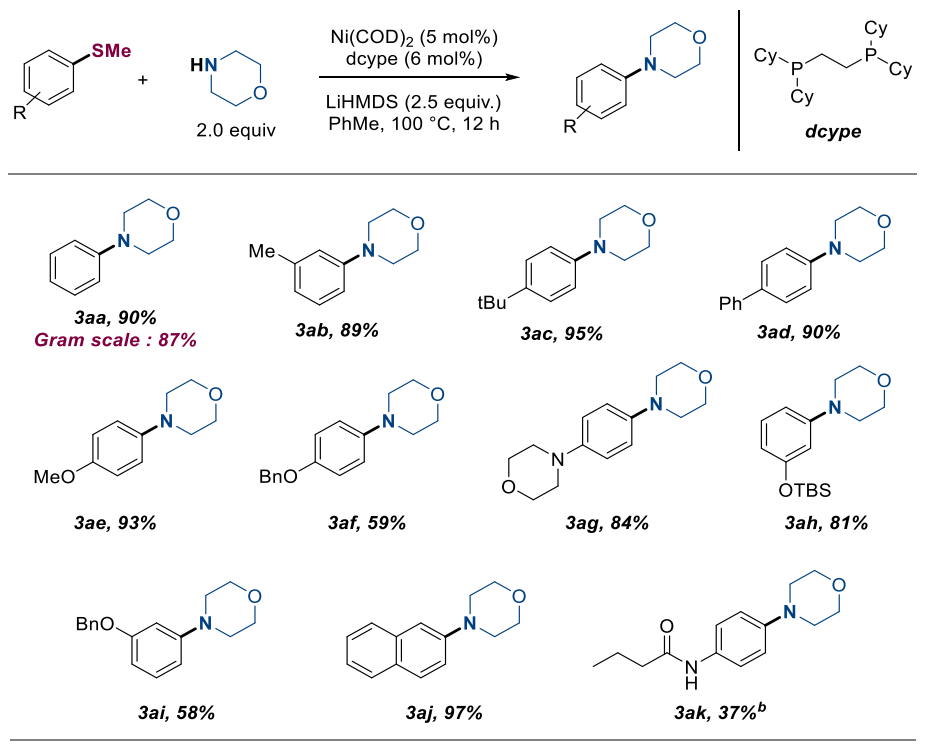

${ }^{a}$ Yield of isolated product (\%). For conditions, see SI. ${ }^{b} 3.5$ equiv. of LiHMDS was used.

Next, we evaluated the scope of the reaction between several thioanisoles and aniline (Table

3). To our delight, the versatility proved to be even higher with this coupling partner. Indeed, electron-neutral (3ba, 3bb, 3bc \& 3bd), electron-rich (3bf, 3bg \& 3bh), and electron-poor (3bi) arenes were competent under the reaction conditions. A bulky thioanisole was also shown to be competent partner, bearing an ortho-methyl (3be). We next tested different heterocyclic (3bj) and bicyclic (3bk \& 3bl) substrates, which all gave the corresponding products in good to excellent yield. To our delight, the reaction also proceeded with a thiomethylether in the benzylic position affording $\mathbf{3 b m}$ in $38 \%$ yield, providing a rare example of a Ni-catalyzed $\mathrm{C}\left(\mathrm{sp}^{3}\right)-\mathrm{N}$ bond formation and a potential alternative to traditional alkylation with toxic benzyl bromide. We finally, derivatized a commercially relevant molecule, MMMP (photoinitiator), which led to the formation of $\mathbf{3 b n}$ in good yield.

Table 3. Substrate scope of thioanisoles with aniline. ${ }^{a}$ 
This document is the Accepted Manuscript version of a Published Work that appeared in final form in ACS Catalysis, copyright (C) American Chemical Society after peer review and technical editing by the publisher. To access the final edited and published work see https://doi.org/10.1021/acscatal.0c00393

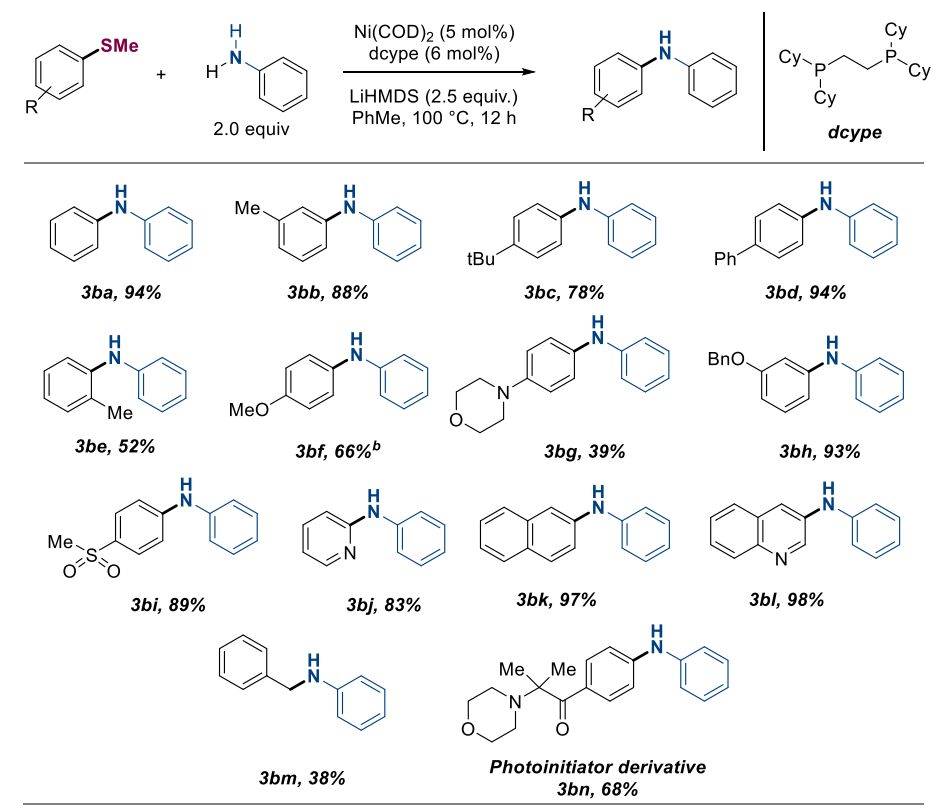

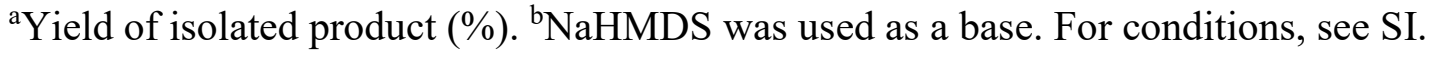

We next tested the applicability of this protocol with different functionalized amines (Table 4).

Primary amines (3ca, 3cb \& 3cc) worked smoothly under the reaction conditions. The catalytic manifold displayed good tolerance toward a variety of functional groups such as aromatic (3cd) and non-aromatic heterocycles (3ce), cyclopropane (3cf), ether (3cg), thioether $(\mathbf{3 c h})$, phenylethyl (3ci), bulky cycloalkyl (3cj) and citronellol moiety (3ck). Chiral amines also worked efficiently under the reaction conditions, providing valuable aryl amines (3cl $\boldsymbol{\&} \mathbf{3} \mathbf{c m})$. Furthermore, secondary amines were competent coupling partners, giving the corresponding tertiary amine products $(\mathbf{3} \mathbf{c n}, \mathbf{3 c o} \& \mathbf{3 c p})$ in moderate to excellent yield. Benzylamine (3cq) was shown to be a competent partner affording the product in $58 \%$ yield, a product which can be further deprotected to release the primary aniline. A set of different benzylic amines were tested such as $p$-methoxybenzyl (3cr), furyl (3cs) and naphthyl (3ct). The coupling product was formed in all cases in moderate to good yield. Several anilines bearing methyl (3cu), methoxy (3cv), naphthyl (3cw) and a highly-bulky 2,6-methylaniline (3cx) worked in good to excellent yield. 
This document is the Accepted Manuscript version of a Published Work that appeared in final form in ACS Catalysis, copyright (C) American Chemical Society after peer review and technical editing by the publisher. To access the final edited and published work see https://doi.org/10.1021/acscatal.0c00393

This methodology was also applied to the arylation of an alkyl chain bearing a 1,2-chloro amine moiety (3cy) whose synthesis was previously developed in our group. ${ }^{22}$ Surprisingly, the ringclosed aziridine product was obtained in a synthetically useful yield of $58 \%$, possibly after the $\mathrm{NH}$-aziridine was generated under the basic reaction conditions. To the best of our knowledge, this is the first Ni-catalyzed Buchwald-Hartwig amination using an aziridine moiety as amine partner. We also performed an intramolecular reaction, affording a rare example of amine-based spirocycle (3cz) in excellent yield. The identity of this species was further confirmed by singlecrystal X-ray analysis. We finally applied this methodology to derivatize a drug, which treats attention deficit hyperactivity disorder, Atomoxetine (3caa) and a natural derivative, $\delta$ Tocopherol (3cab). In both cases, the expected product was obtained in high yield. Overall, we have provided a Ni-based catalytic manifold which can compete with the scope and functional group tolerance of previously reported palladium systems. ${ }^{18}$

Table 4. Substrate scope of amines. ${ }^{a}$ 
This document is the Accepted Manuscript version of a Published Work that appeared in final form in ACS Catalysis, copyright (C) American Chemical Society after peer review and technical editing by the publisher. To access the final edited and published work see https://doi.org/10.1021/acscatal.0c00393

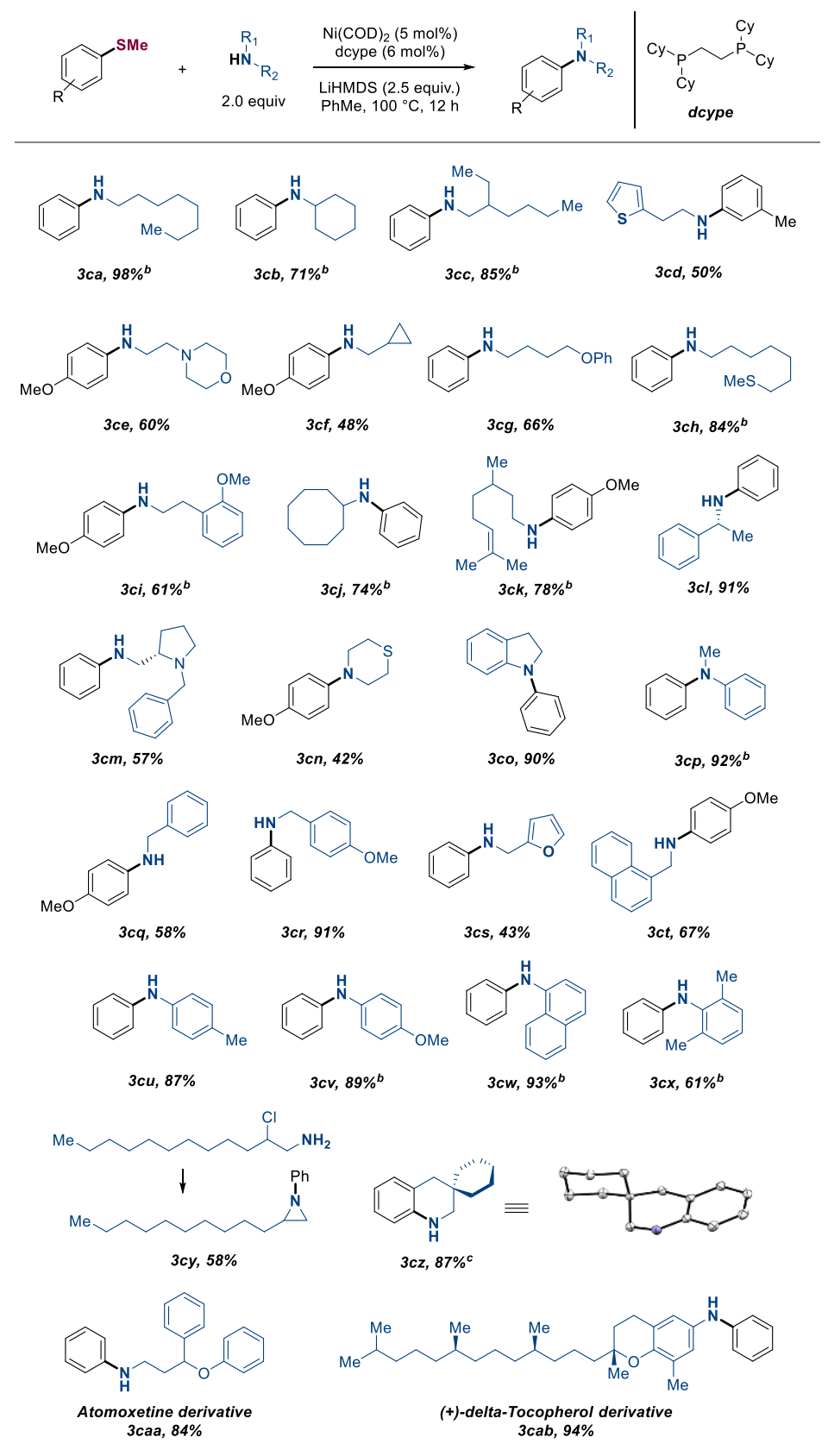

${ }^{a}$ Yield of isolated product (\%). ${ }^{\mathrm{b}} \mathrm{NaHMDS}$ was used as a base. For conditions, see SI. ${ }^{\mathrm{c}} 1.25$ equiv. of LiHMDS were used.

Evaluation of the mechanism of the Ni-catalyzed amination of thioethers. The abovementioned ability of nickel to cover different oxidation states, prompted us to start investigating 
This document is the Accepted Manuscript version of a Published Work that appeared in final form in ACS Catalysis, copyright (C) American Chemical Society after peer review and technical editing by the publisher. To access the final edited and published work see https://doi.org/10.1021/acscatal.0c00393

the first step of a possible catalytic cycle, the oxidative addition of Ar-SMe. Pioneer work was reported by Itami's group on the oxidative addition of Ar-OPiv using a Ni-dcype system. ${ }^{21}$ Very recently we have also started investigating this step in $\mathrm{C}-\mathrm{S}$ bond metathesis reaction using a similar catalytic system. ${ }^{19 b}$ In order to study the oxidative addition step and gain information on potential deactivation products and the lifetime of these species, we decided to start our investigation using thioanisole 1a, $\mathrm{Ni}(\mathrm{COD})_{2}$ and dcype. After 16 hours at $80^{\circ} \mathrm{C}$, formation of complex 5 was observed by ${ }^{31} \mathrm{P}\{\mathrm{H}\}$ NMR with resonances at $\delta=65$ and 61 , giving the oxidative addition product in $75 \%$ yield (see SI). The identity of this compound was confirmed by single crystal X-ray analysis (Scheme 2, A). It is worth noting that this complex seems to be more stable than the species isolated from the oxidative addition of aryl halides, which rapidly decomposes to nickel(I) species. ${ }^{17}$

We then investigated the putative transmetallation step by reacting complex $\mathbf{5}$ and the isolated Li-anilide salt $\mathbf{2 b a - L i}$ (Scheme 2, B). Interestingly, the reaction was very slow at room temperature, but upon heating to $90{ }^{\circ} \mathrm{C}$ led to a complicated mixture with clear formation of the final coupling product and $\mathrm{Ni}(0)(\text { dcype })_{2}\left({ }^{31} \mathrm{P}\{\mathrm{H}\} \mathrm{NMR} \delta=43\right)$. This inevitably hampered the isolation of the transmetallation product suggesting that this step is featured with a higher activation energy barrier when compared to that of the reductive elimination step. In order to evaluate a possible resting state of the catalytic cycle and thus gather information about the turnover-limiting step, we performed in situ NMR analysis under catalytic conditions, using thioanisole and morpholine as benchmarch substrates (Scheme 2, C). To our delight, it was possible to observe an accumulation of the oxidative addition product ((dcype)NiArSMe) in the first hour, which remained as the major species during the course of the reaction (see SI). 
This document is the Accepted Manuscript version of a Published Work that appeared in final form in ACS Catalysis, copyright (C) American Chemical Society after peer review and technical editing by the publisher. To access the final edited and published work see https://doi.org/10.1021/acscatal.0c00393
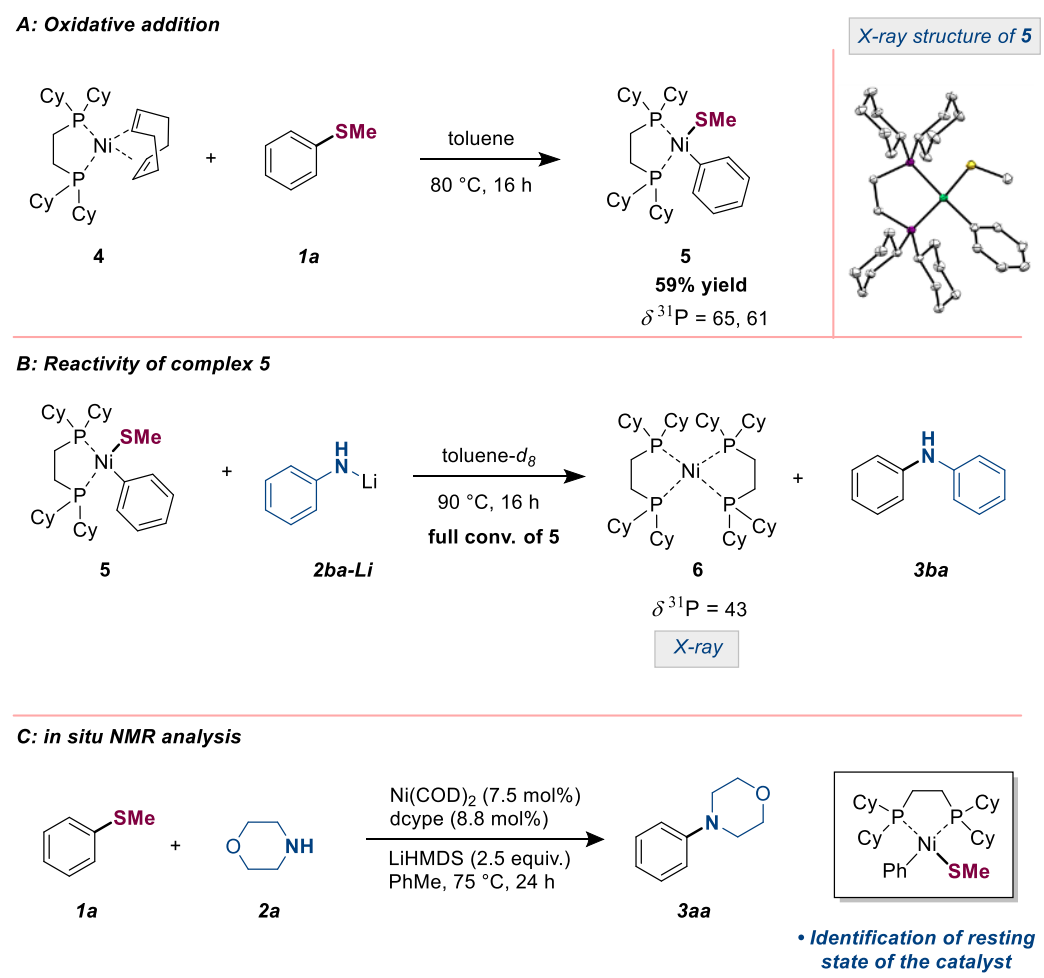

Scheme 2. Mechanistic investigation. A) isolation of the oxidative addition product; B) transmetallation step; C) in situ NMR analysis of a catalytic reaction.

This observation, combined with the kinetic competence of this complex, suggest that it is the resting state of this catalytic system. Since the putative transmetallation nickel complex is formed after the turnover-limiting step, its isolation proved to be particularly challenging. Thus, we wondered whether this product could be synthesized through an alternative pathway with a lower energy barrier. We reasoned that transmetallation from a nickel halide species would possibly provide an easier route for the isolation of this potentially highly reactive complex. ${ }^{23}$ Notably, the isolation of the transmetallation intermediate in a Ni-catalyzed Buchwald-Hartwig reaction has not been previously reported. Thus, we commenced our investigation reacting bromobenzene with in situ formed $\mathrm{Ni}$ complex 4. Interestingly, the reaction led to formation of 
This document is the Accepted Manuscript version of a Published Work that appeared in final form in ACS Catalysis, copyright (C) American Chemical Society after peer review and technical editing by the publisher. To access the final edited and published work see https://doi.org/10.1021/acscatal.0c00393

dibromo nickel species presumably due to an undesired side reaction (see SI). In contrast to Hartwig's observations, who employed a nickel-BINAP system, we did not observe formation of $\mathrm{Ni}(\mathrm{I})$ species. We surmise that the strongly donating nature of dcype ligand is somewhat influencing the reaction giving rise to a stable Ni(II) species. ${ }^{24}$ As previously observed in similar cases, ${ }^{25}$ performing the same reaction in the presence of one equivalent of benzonitrile, had a tremendous impact on the outcome, leading, this time, to the desired oxidative addition product $\mathbf{8}$ in $80 \%$ yield at room temperature (Scheme 3). With this compound, we then started evaluating the reactivity toward $\mathrm{Li}$-amide $\mathbf{2 b a - L i}$. Treating complex $\mathbf{8}$ with an excess of $\mathrm{Li}$-anilide resulted in a complicated mixture of products. Thus, we wondered whether the choice of a secondary amine and a variation of the cation may ease the isolation and the study of this step. Gratifyingly, treatment of complex $\mathbf{8}$ with 1 equivalent of $\mathrm{Na}$-anilide $\mathbf{2 c p - N a}$ led to a cleaner reaction with distinct formation of a new set of doublets $\left({ }^{31} \mathrm{P}\{\mathrm{H}\} \delta=57,49\right)$ and almost full conversion after 5 minutes at room temperature (Scheme 3). Remarkably, and regardless of the low stability of the organometallic species 9 , we were able to isolate it at low temperature (57\% yield) and confirm its identity by single crystal X-ray analysis.

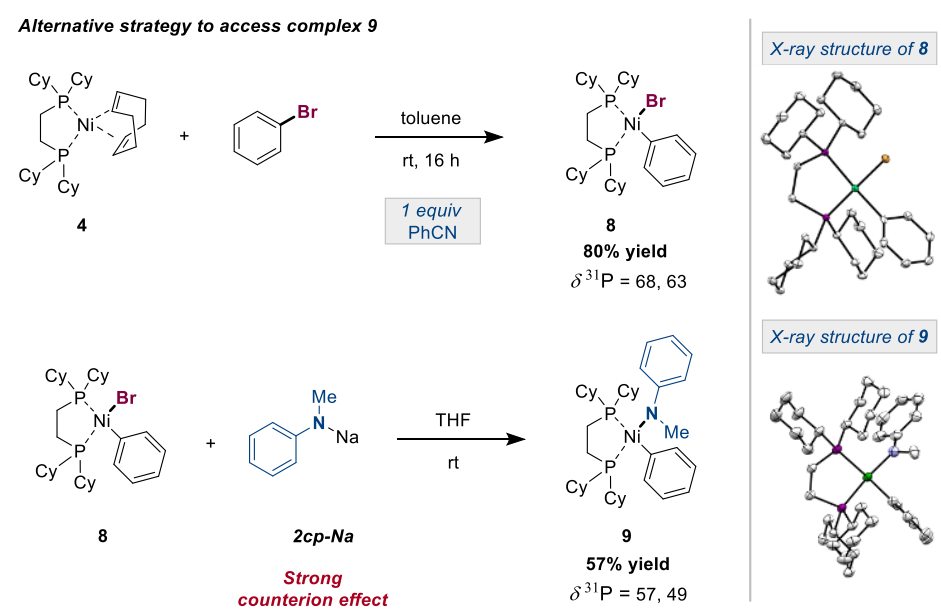

Scheme 3. Alternative strategy to access complex 9. 
This document is the Accepted Manuscript version of a Published Work that appeared in final form in ACS Catalysis, copyright (C) American Chemical Society after peer review and technical editing by the publisher. To access the final edited and published work see https://doi.org/10.1021/acscatal.0c00393

Because oxidative addition and reductive elimination at a Ni-center have often been reported to give formation of $\mathrm{Ni}(\mathrm{III})$ or $\mathrm{Ni}(\mathrm{I})$ species, a clarification on this matter would be highly valuable for the development of new catalytic systems and the improvement of existing ones. ${ }^{25 a-f}$ In addition, while reductive elimination of $\mathrm{C}-\mathrm{N}$ bonds has been extensively studied under palladium-catalysis, ${ }^{26 a-d}$ the analogous step in nickel-catalysis has been rarely observed. ${ }^{27 a, b}$ Hence, we set out to study the stability of complex 9 at different temperatures monitoring by in situ ${ }^{1} \mathrm{H}$ and ${ }^{31} \mathrm{P}$ NMR spectroscopy (see SI). The organometallic species 9 proved to be highly reactive even at room temperature with spontaneous formation of two new singlets $\left({ }^{31} \mathrm{P}\{\mathrm{H}\} \delta=\right.$ $48,44)$ and a resulting NMR-pattern consistent with the reductive elimination product. Performing the reaction at $55^{\circ} \mathrm{C}$ led to preferential formation of only one resonance $\left({ }^{31} \mathrm{P}\{\mathrm{H}\} \delta=\right.$ 48) which is proposed to be an adduct between the product and Ni-dcype.

As the catalytic reaction is performed in the presence of a slight excess of phosphine relative to nickel, we performed the same transformation adding one equivalent of ligand. Interestingly, upon heating, it was possible to observe consumption of both complex 9 and free phosphine ligand together with concomitant formation of the diligated nickel species $\mathbf{6}$ as the sole organometallic product of the reaction (Scheme 4). These stoichiometric experiments suggest that, in the presence of an excess of ligand, formation of complex 6 is preferred. However, due to the high concentration of amine under catalytic conditions we cannot exclude formation of any $\mathrm{Ni}(0)$-product adduct. 
This document is the Accepted Manuscript version of a Published Work that appeared in final form in ACS Catalysis, copyright (C) American Chemical Society after peer review and technical editing by the publisher. To access the final edited and published work see https://doi.org/10.1021/acscatal.0c00393

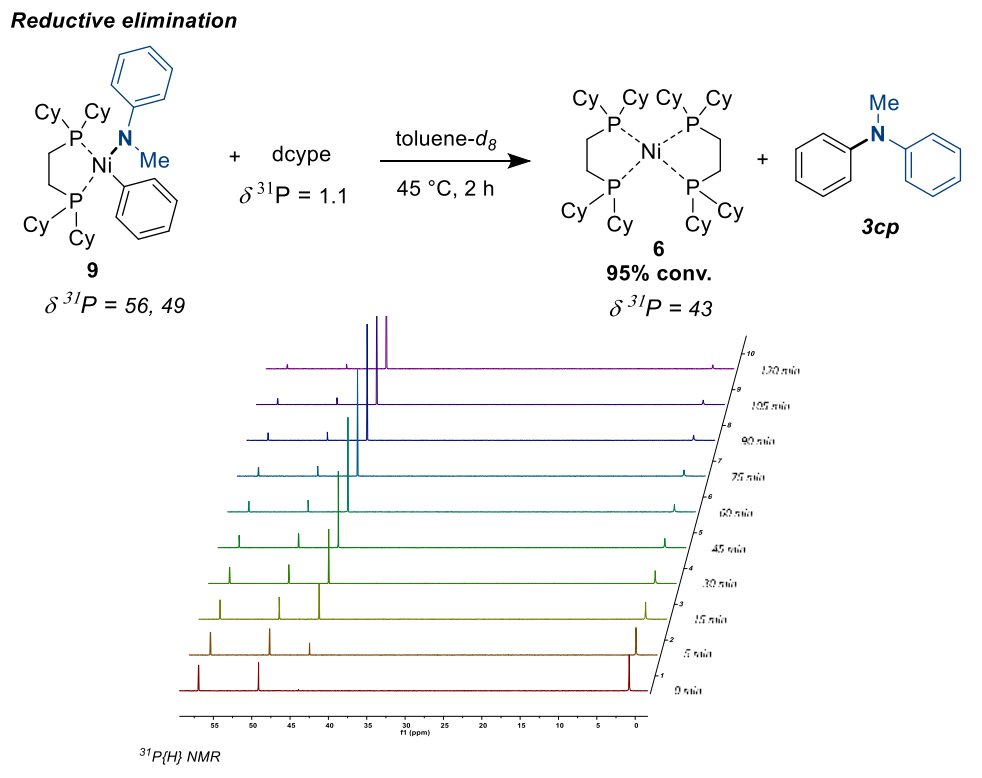

Scheme 4. Study of the reductive elimination step.

In order to complete our study, we sought further information from kinetic investigations (Scheme 5). We started analyzing a possible deactivation of the catalyst or product inhibition, as described by Blackmond ${ }^{28}$ and Burés, ${ }^{29 a, b}$ by carrying out a set of three simple experiments where the concentration of the reagents is varied while keeping the concentration of the catalyst constant (Scheme 5). It was evident from these experiments that there was no significant catalyst deactivation or product inhibition, a result which motivated us to continue the study by investigating the kinetic orders of the catalyst and the reagents. By varying the concentration of the catalyst $(5.0 \mathrm{~mol} \%, 7.5 \mathrm{~mol} \%, 10 \mathrm{~mol} \%)$, a first order dependence on catalyst concentration was observed. ${ }^{30 \mathrm{a}-\mathrm{c}}$ By further varying the equivalents of phosphine ligands $(1.0,1.5$ and 2.0 equiv) and thioanisole, it was possible to determine a zero-order dependence on both ligand and thioanisole concentrations. Those combined results suggest that the turnover-limiting step does not involve any ligand association or dissociation step nor any reaction between the catalyst and the thioanisole substrate. These results were further confirmed using the initial rate approach (see 
This document is the Accepted Manuscript version of a Published Work that appeared in final form in ACS Catalysis, copyright (C) American Chemical Society after peer review and technical editing by the publisher. To access the final edited and published work see https://doi.org/10.1021/acscatal.0c00393

SI). The determination of the order in morpholine reagent turned out to be more complicated because an increase in its concentration led to a less homogeneous system. Preliminary analysis using classic initial rates method suggested an order of morpholine of 0.46 , however, the analysis using VTNA gave first order in morpholine. Although we cannot completely rule out an alternative mechanistic pathway, we believe that VTNA method provides an order in morpholine which is more consistent with our proposed mechanism (vide infra).

To test the efficiency of this methodology, we performed this reaction on a larger scale using as little as $0.5 \mathrm{~mol} \%$ of catalyst to determine a TON of 100 , showing the potential of this reaction for preparative applications. 
This document is the Accepted Manuscript version of a Published Work that appeared in final form in ACS Catalysis, copyright (C) American Chemical Society after peer review and technical editing by the publisher. To access the final edited and published work see https://doi.org/10.1021/acscatal.0c00393

\section{Kinetic Analysis}
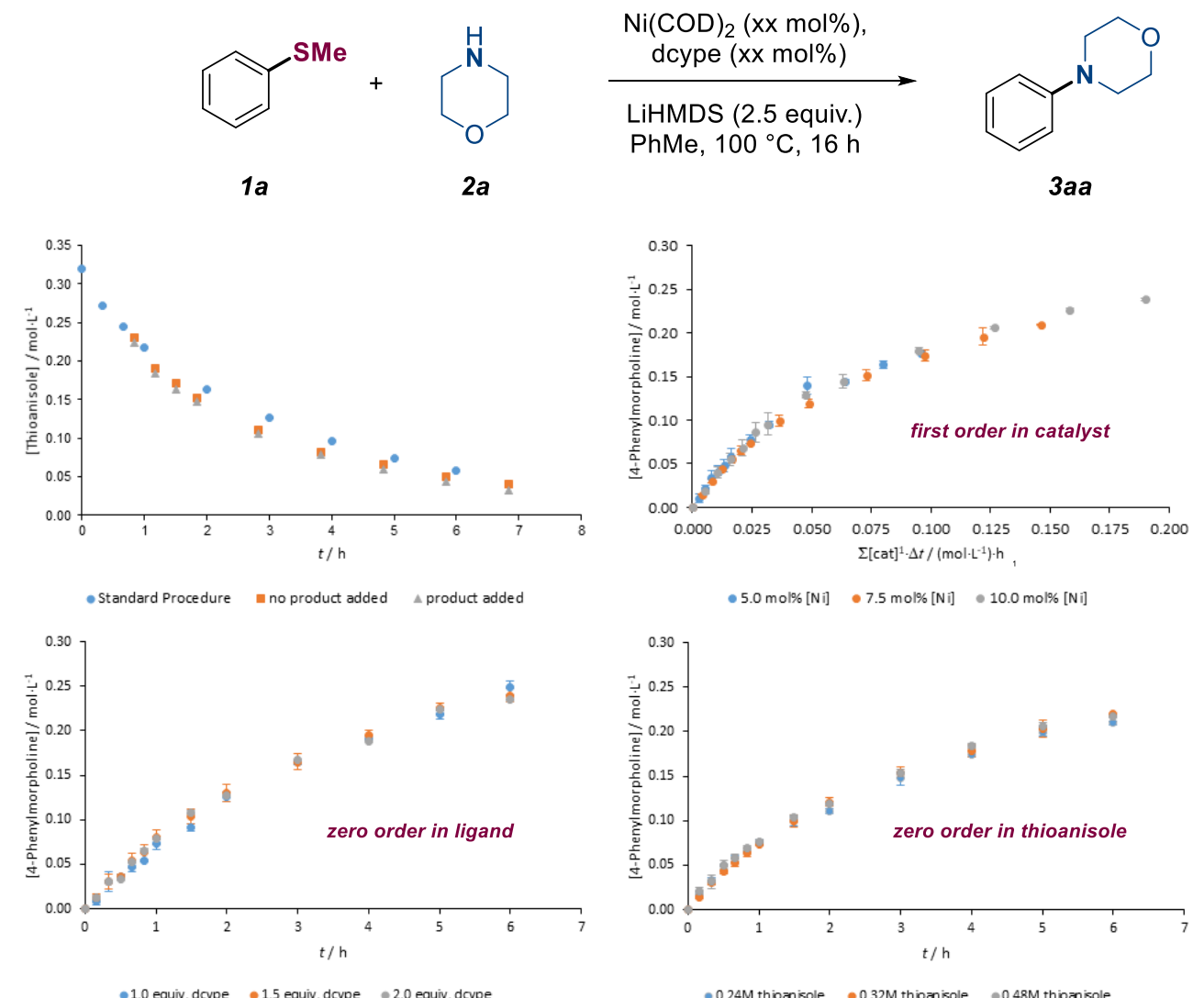

$\bullet 1.0$ equiv. doype $\quad \cdot 1.5$ equiv. dcype $\quad 2.0$ equiv. dcype

$\bullet 0.24 \mathrm{M}$ thioanisole $\quad \cdot 0.32 \mathrm{M}$ thioanisole $\quad \cdot 0.48 \mathrm{M}$ thioanisole

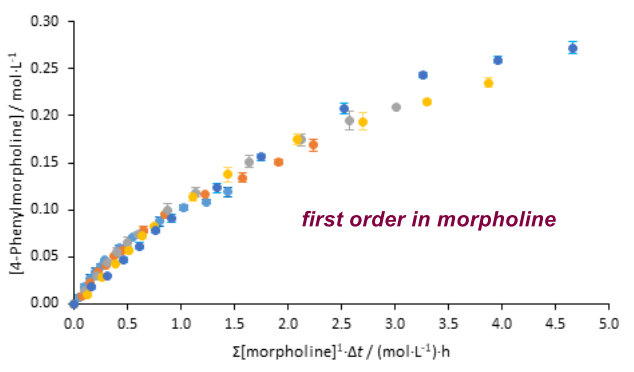

$\bullet 0.32 \mathrm{M}$ morpholine $\bullet 0.48 \mathrm{M}$ morpholine $\bullet 0.64 \mathrm{M}$ morpholine

$0.80 \mathrm{M}$ morpholine $\bullet 0.96 \mathrm{M}$ morpholine

Scheme 5. Kinetic analysis.

Once the kinetic profile of this transformation had been investigated, we tested the catalytic activity of the isolated complexes $(4,5 \&$ 9) using $7.5 \mathrm{~mol} \%$ of each complex and thioanisole and aniline as model substrates (Scheme 6, A). To our delight all the complexes were found to be kinetically and catalytically competent with very similar kinetic profiles (see SI). As expected, 
This document is the Accepted Manuscript version of a Published Work that appeared in final form in ACS Catalysis, copyright (C) American Chemical Society after peer review and technical editing by the publisher. To access the final edited and published work see https://doi.org/10.1021/acscatal.0c00393

complex 9 showed immediate formation of $7.5 \%$ of product and subsequently reacted with a similar initial rate when compared to the model reaction, confirming that this intermediate is placed after the turnover-limiting step of the reaction (see SI).

Based on the above-mentioned experiments we herein propose a catalytic cycle whereby activation of thioanisole occurs through oxidative addition onto a $\mathrm{Ni}(0)$ complex, followed by a subsequent transmetallation with in situ formed $\mathrm{Li}-$ or $\mathrm{Na}$-anilide species that leads to formation of nickel complex 9 which undergoes rapid reductive elimination to release the product and regenerate the metal catalyst (Scheme 6, B). Under these conditions, the oxidative addition adduct is the resting state and the transmetallation step is the turnover-limiting step.
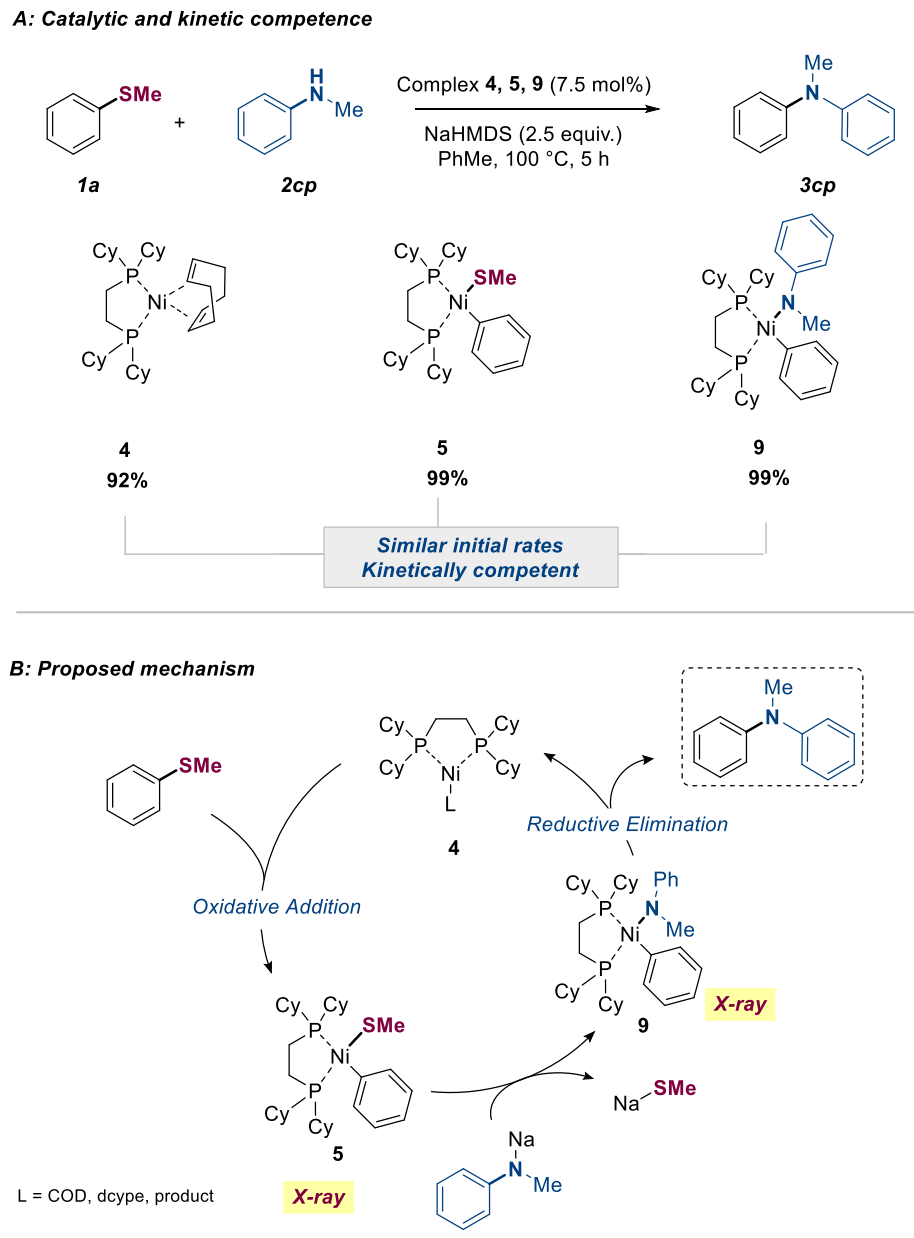
This document is the Accepted Manuscript version of a Published Work that appeared in final form in ACS Catalysis, copyright (C) American Chemical Society after peer review and technical editing by the publisher. To access the final edited and published work see https://doi.org/10.1021/acscatal.0c00393

Scheme 6. Mechanistic investigation. A) catalytic competence of isolated Ni-complexes; B) proposed mechanism.

\section{CONCLUSION}

We have shown that a nickel-dcype system can be used to promote Buchwald-Hartwig amination using aryl thioethers as coupling partners. The protocol developed has a good substrate scope and can be used for late-stage functionalization.

A detailed mechanistic study of this transformation has been carried out whose key findings can be summarized as follows:

(1) The combination of a Ni-dcype system using thioethers as electrophiles leads to a cleaner stoichiometric oxidative addition reaction when compared to aryl halides, and the isolated oxidative addition product are stable at room temperature without any observed disproportionation.

(2) In contrast to the previously reported system for Buchwald-Hartwig reaction, in which the $\mathrm{Ni}(0)$ species was the resting state of the reaction, in situ NMR investigation show that the oxidative addition complex is likely the resting state of this transformation. This finding was also supported by kinetic investigation, where a zero-order dependence on thioanisole concentration was observed. These results are best explained by a turnoverlimiting transmetallation step.

(3) Despite the fleeting nature of the transmetallation intermediate, which is the product of the turnover-limiting step of the reaction, it was possible to isolate the transmetallation 
This document is the Accepted Manuscript version of a Published Work that appeared in final form in ACS Catalysis, copyright (C) American Chemical Society after peer review and technical editing by the publisher. To access the final edited and published work see https://doi.org/10.1021/acscatal.0c00393

complex through a distinct synthetic organometallic pathway and thus monitor the $\mathrm{C}-\mathrm{N}$ bond reductive elimination step by NMR spectroscopy.

In conclusion, we have successfully developed a broadly applicable protocol for the BuchwaldHartwig amination which enables the use of aryl thioethers as coupling partners under Nicatalysis. The key mechanistic findings have shed light on a timely topic in catalysis: the oxidation state in nickel-catalyzed cross-coupling reactions. Strong support has been presented for a $\mathrm{Ni}(0)-\mathrm{Ni}(\mathrm{II})$ pathway. In a broader context, we believe that these findings will help the development of new nickel-catalyzed Buchwald-Hartwig reactions.

\section{AUTHOR INFORMATION}

Corresponding Author

* bill.morandi@org.chem.ethz.ch.

\section{Author Contributions}

The manuscript was written through contributions of all authors. All authors have given approval to the final version of the manuscript.

† Alessandro Bismuto and Tristan Delcaillau contributed equally.

\section{ASSOCIATED CONTENT}

Supporting Information.

The following files are available free of charge.

Details of experimental procedures and spectroscopic data (PDF).

X-ray Structures (CIF). 
This document is the Accepted Manuscript version of a Published Work that appeared in final form in ACS Catalysis, copyright (C) American Chemical Society after peer review and technical editing by the publisher. To access the final edited and published work see https://doi.org/10.1021/acscatal.0c00393

\section{ACKNOWLEDGMENTS}

This work was supported by Swiss National Science Foundation (SNSF 184658) and ETH Zürich. We thank the NMR, MS and X-ray departments of ETH Zürich (Dr. Nils Trapp) for technical assistance. All the authors thank Dr. M. A. Rivero for fruitful discussions. The authors thank an anonymous reviewer for thoughtful suggestions regarding the kinetic studies.

\section{REFERENCES}

(1) a) Cordovilla, C.; Bartolomé, C.; Martínez-Ilarduya, J. M.; Espinet, P. The Stille Reaction, 38 Years Later. ACS Catal. 2015, 5, 3040-3053; b) Suzuki, A. Cross-Coupling Reactions of Organoboranes: An Easy Way to Construct C-C Bonds (Nobel Lecture). Angew. Chem. Int. Ed. 2011, 50, 6723-6733; c) Knappke, C. E. I.; Jacobi von Wangelin, A. 35 Years of Palladium-Catalyzed Cross-Coupling with Grignard Reagents: How Far Have We Come? Chem. Soc. Rev. 2011, 40, 4948.

(2) a) Hartwig, J. F. Carbon-heteroatom Bond Formation Catalysed by Organometallic Complexes. Nature 2008, 455, 314-322; b) Hartwig, J. F. Transition Metal Catalyzed Synthesis of Arylamines and Aryl Ethers from Aryl Halides and Triflates: Scope and Mechanism. Angew. Chem. Int. Ed. 1998, 37, 2046-2067; c) Ruiz-Castillo, P.; Buchwald, S. L. Applications of Palladium-Catalyzed C-N Cross-Coupling Reactions. Chem. Rev. 2016, 116, 12564-12649; d) Dorel, R.; Grugel, C. P.; Haydl, A. The Buchwald-Hartwig Amination after 25 Years. Angew. Chem. Int. Ed. 2019, 58, 17118-17129. 
This document is the Accepted Manuscript version of a Published Work that appeared in final form in ACS Catalysis, copyright (C) American Chemical Society after peer review and technical editing by the publisher. To access the final edited and published work see https://doi.org/10.1021/acscatal.0c00393

(3) Devendar, P.; Qu, R.-Y.; Kang, W.-M.; He, B.; Yang, G.-F. Palladium-Catalyzed CrossCoupling Reactions: A Powerful Tool for the Synthesis of Agrochemicals. J. Agric. Food Chem. 2018, 66, 8914-8934.

(4) a) Torborg, C.; Beller, M. Recent Applications of Palladium-Catalyzed Coupling Reactions in the Pharmaceutical, Agrochemical, and Fine Chemical Industries. Adv. Synth. Catal. 2009, 351, 3027-3043; b) Corbet, J. P.; Mignani, G. Selected Patented Cross-Coupling Reaction Technologies. Chem. Rev. 2006, 106, 2651-2710.

(5) a) Uehling, M. R.; King, R. P.; Krska, S. W.; Cernak, T.; Buchwald, S. L. Pharmaceutical Diversification via Palladium Oxidative Addition Complexes. Science 2019, 363, 405408; b) Roy, D.; Uozumi, Y. Recent Advances in Palladium-Catalyzed Cross-Coupling Reactions at Ppm to Ppb Molar Catalyst Loadings. Adv. Synth. Catal. 2018, 360, 602625.

(6) a) Ku, Y. Y.; Chan, V. S.; Christesen, A.; Grieme, T.; Mulhern, M.; Pu, Y. M.; Wendt, M. D. Development of a Convergent Large-Scale Synthesis for Venetoclax, a First-inClass BCL-2 Selective Inhibitor. J. Org. Chem. 2019, 84, 4814-4829; b) Sperry, J. B.; Price Wiglesworth, K. E.; Edmonds, I.; Fiore, P.; Boyles, D. C.; Damon, D. B.; Dorow, R. L.; Piatnitski Chekler, E. L.; Langille, J.; Coe, J. W. Kiloscale Buchwald-Hartwig Amination: Optimized Coupling of Base-Sensitive 6-Bromoisoquinoline-1-Carbonitrile with (s)-3-Amino-2-Methylpropan-1-Ol. Org. Process Res. Dev. 2014, 18, 1752-1758.

(7) a) Shen, Q.; Ogata, T.; Hartwig, J. F. Highly Reactive, General and Long-Lived Catalysts for Palladium-Catalyzed Amination of Heteroaryl and Aryl Chlorides, Bromides, and 
This document is the Accepted Manuscript version of a Published Work that appeared in final form in ACS Catalysis, copyright (C) American Chemical Society after peer review and technical editing by the publisher. To access the final edited and published work see https://doi.org/10.1021/acscatal.0c00393

Iodides: Scope and Structure-Activity Relationships. J. Am. Chem. Soc. 2008, 130, 8564-8564; b) Ogata, T.; Hartwig, J. F. Palladium-Catalyzed Amination of Aryl and Heteroaryl Tosylates at Room Temperature. J. Am. Chem. Soc. 2008, 130, 13848-13849.

(8) a) Shekhar, S.; Ryberg, P.; Hartwig, J. F.; Mathew, J. S.; Blackmond, D. G.; Strieter, E. R.; Buchwald, S. L. Reevaluation of the Mechanism of the Amination of Aryl Halides Catalyzed by BINAP-Ligated Palladium Complexes. J. Am. Chem. Soc. 2006, 128, 35843591; b) Bariwal, J.; Van Der Eycken, E. C-N Bond Forming Cross-Coupling Reactions: An overview. Chem. Soc. Rev. 2013, 42, 9283-9303.

(9) Hartwig, J. Palladium-Catalyzed Amination of Aryl Halides: Mechanism and Rational Catalyst Design. Synlett 1997, 1997, 329-340.

(10) a) Paul, F.; Patt, J.; Hartwig, J. F. Palladium-Catalyzed Formation of Carbon-Nitrogen Bonds. Reaction Intermediates and Catalyst Improvements in the Hetero CrossCoupling of Aryl Halides and Tin Amides. J. Am. Chem. Soc. 1994, 116, 5969-5970; b) Louie, J.; Hartwig, J. F. Palladium-Catalyzed Synthesis of Arylamines from Aryl Halides. Mechanistic Studies Lead to Coupling in the Absence of Tin Reagents.

Tetrahedron Lett. 1995, 36, 3609-3612; c) Guram, A. S.; Rennels, R. A.; Buchwald, S. L. A Simple Catalytic Method for the Conversion of Aryl Bromides to Arylamines. Angew. Chem. Int. Ed. 1995, 34, 1348-1350.

(11) a) Lundgren, R. J.; Stradiotto, M. Addressing Challenges in Palladium-Catalyzed CrossCoupling Reactions through Ligand Design. Chem. Eur. J. 2012, 18, 9758-9769; b) Dennis, J. M.; White, N. A.; Liu, R. Y.; Buchwald, S. L. Breaking the Base Barrier: An 
This document is the Accepted Manuscript version of a Published Work that appeared in final form in ACS Catalysis, copyright (C) American Chemical Society after peer review and technical editing by the publisher. To access the final edited and published work see https://doi.org/10.1021/acscatal.0c00393

Electron-Deficient Palladium Catalyst Enables the Use of a Common Soluble Base in C-N Coupling. J. Am. Chem. Soc. 2018, 140, 4721-4725; c) Ingoglia, B. T.; Wagen, C.

C.; Buchwald, S. L. Biaryl Monophosphine Ligands in Palladium-Catalyzed C-N

Coupling: An Updated User's Guide. Tetrahedron 2019, 75, 4199-4211; d) Surry, D.

S.; Buchwald, S. L. Biaryl Phosphane Ligands in Palladium-Catalyzed Amination.

Angew. Chem. Int. Ed. 2008, 47, 6338-6361.

(12) a) Su, B.; Cao, Z. C.; Shi, Z. J. Exploration of Earth-Abundant Transition Metals (Fe, Co, and Ni) as Catalysts in Unreactive Chemical Bond Activations. Acc. Chem. Res. 2015, 48, 886-896; b) Chirik, P.; Morris, R. Getting Down to Earth: The Renaissance of Catalysis with Abundant Metals. Acc. Chem. Res. 2015, 48, 2495.

(13) a) Ananikov, V. P. Nickel: The "Spirited Horse" of Transition Metal Catalysis. ACS Catal. 2015, 5, 1964-1971; b) Harry, N. A.; Saranya, S.; Ujwaldev, S. M.; Anilkumar, G. Recent Advances and Prospects in Nickel-Catalyzed C-H Activation. Catal. Sci. Technol. 2019, 9, 1726-1743; c) Tasker, S. Z.; Standley, E. A.; Jamison, T. F. Recent Advances in Homogeneous Nickel Catalysis. Nature 2014, 509, 299-309; d) Chartoire, A.; Lesieur, M.; Slawin, A. M. Z.; Nolan, S. P.; Cazin, C. S. J. Highly Active WellDefined Palladium Precatalysts for the Efficient Amination of Aryl Chlorides. Organometallics 2011, 30, 4432-4436.

(14) a) Cornella, J.; Gómez-Bengoa, E.; Martin, R. Combined Experimental and Theoretical Study on the Reductive Cleavage of Inert C-O Bonds with Silanes: Ruling out a Classical Ni(0)/Ni(II) Catalytic Couple and Evidence for Ni(I) Intermediates. J. Am. Chem. Soc. 2013, 135, 1997-2009; b) Yin, G.; Kalvet, I.; Englert, U.; Schoenebeck, F. 
This document is the Accepted Manuscript version of a Published Work that appeared in final form in ACS Catalysis, copyright (C) American Chemical Society after peer review and technical editing by the publisher. To access the final edited and published work see https://doi.org/10.1021/acscatal.0c00393

Fundamental Studies and Development of Nickel-Catalyzed Trifluoromethylthiolation of Aryl Chlorides: Active Catalytic Species and Key Roles of Ligand and Traceless MeCN Additive Revealed. J. Am. Chem. Soc. 2015, 137, 4164-4172; c) Matsubara, K.; Fukahori, Y.; Inatomi, T.; Tazaki, S.; Yamada, Y.; Koga, Y.; Kanegawa, S.; Nakamura, T. Monomeric Three-Coordinate N-Heterocyclic Carbene Nickel(I) Complexes: Synthesis, Structures, and Catalytic Applications in Cross-Coupling Reactions.

Organometallics 2016, 35, 3281-3287; d) Clark, J. S. K.; Lavoie, C. M.; MacQueen, P. M.; Ferguson, M. J.; Stradiotto, M. A Comparative Reactivity Survey of Some Prominent Bisphosphine Nickel(II) Precatalysts in C-N Cross-Coupling. Organometallics 2016, 35, 3248-3254; e) Pappas, I.; Treacy, S.; Chirik, P. J. Alkene Hydrosilylation Using Tertiary Silanes with $\alpha$-Diimine Nickel Catalysts. Redox-Active Ligands Promote a Distinct Mechanistic Pathway from Platinum Catalysts. ACS Catal. 2016, 6, 4105-4109; f) Manzoor, A.; Wienefeld, P.; Baird, M. C.; Budzelaar, P. H. M. Catalysis of Cross-Coupling and Homocoupling Reactions of Aryl Halides Utilizing Ni(0), Ni(I), and Ni(II) Precursors; Ni(0) Compounds as the Probable Catalytic Species but Ni(I) Compounds as Intermediates and Products. Organometallics 2017, 36, 35083519; g) Bajo, S.; Laidlaw, G.; Kennedy, A. R.; Sproules, S.; Nelson, D. J. Oxidative Addition of Aryl Electrophiles to a Prototypical Nickel(0) Complex: Mechanism and Structure/Reactivity Relationships. Organometallics 2017, 36, 1662-1672.

(15) a) Lavoie, C. M.; McDonald, R.; Johnson, E. R.; Stradiotto, M. Bisphosphine-Ligated Nickel Pre-Catalysts in C(Sp2)-N Cross-Couplings of Aryl Chlorides: A Comparison of Nickel(I) and Nickel(II). Adv. Synth. Catal. 2017, 359, 2972-2980; b) Soler-Yanes, R.; 
This document is the Accepted Manuscript version of a Published Work that appeared in final form in ACS Catalysis, copyright (C) American Chemical Society after peer review and technical editing by the publisher. To access the final edited and published work see https://doi.org/10.1021/acscatal.0c00393

Arribas-Álvarez, I.; Guisán-Ceinos, M.; Buñuel, E.; Cárdenas, D. J. Ni Catalyzes the Regioselective Cross-Coupling of Alkylzinc Halides and Propargyl Bromides to Allenes. Chem. Eur. J. 2017, 23, 1584-1590; c) Guard, L. M.; Mohadjer Beromi, M.; Brudvig, G. W.; Hazari, N.; Vinyard, D. J. Comparison of Dppf-Supported Nickel Precatalysts for the Suzuki-Miyaura Reaction: The Observation and Activity of Nickel(I). Angew. Chem. Int. Ed. 2015, 54, 13352-13356; d) Pandey, D. K.; Ankade, S. B.; Ali, A.; Vinod, C. P.; Punji, B. Nickel-Catalyzed C-H Alkylation of Indoles with Unactivated Alkyl Chlorides: Evidence of a Ni(I)/Ni(III) Pathway. Chem. Sci. 2019, 10, 9493-9500.

(16) a) Borzenko, A.; Rotta-Loria, N. L.; MacQueen, P. M.; Lavoie, C. M.; McDonald, R.; Stradiotto, M. Nickel-Catalyzed Monoarylation of Ammonia. Angew. Chem. Int. Ed. 2015, 54, 3773-3777; b) Lavoie, C. M.; MacQueen, P. M.; Stradiotto, M. NickelCatalyzed N-Arylation of Primary Amides and Lactams with Activated (Hetero)Aryl Electrophiles. Chem. Eur. J. 2016, 22, 18752-18755; c) Tassone, J. P.; MacQueen, P. M.; Lavoie, C. M.; Ferguson, M. J.; McDonald, R.; Stradiotto, M. Nickel-Catalyzed N Arylation of Cyclopropylamine and Related Ammonium Salts with (Hetero)Aryl (Pseudo)Halides at Room Temperature. ACS Catal. 2017, 7, 6048-6059; d) MacQueen, P. M.; Stradiotto, M. Nickel-Catalyzed Cross-Coupling of Ammonia or Primary Alkylamines with (Hetero)Aryl Sulfamates, Carbamates, or Pivalates. Synlett 2017, 28, 1652-1656; e) Clark, J. S. K.; Voth, C. N.; Ferguson, M. J.; Stradiotto, M. Evaluating 1,1'-Bis(Phosphino)Ferrocene Ancillary Ligand Variants in the Nickel-Catalyzed C-N Cross-Coupling of (Hetero)Aryl Chlorides. Organometallics 2017, 36, 679-686. 
This document is the Accepted Manuscript version of a Published Work that appeared in final form in ACS Catalysis, copyright (C) American Chemical Society after peer review and technical editing by the publisher. To access the final edited and published work see https://doi.org/10.1021/acscatal.0c00393

(17) Ge, S.; Green, R. A.; Hartwig, J. F. Controlling First-Row Catalysts: Amination of Aryl and Heteroaryl Chlorides and Bromides with Primary Aliphatic Amines Catalyzed by a BINAP-Ligated Single-Component Ni(0) Complex. J. Am. Chem. Soc. 2014, 136, $1617-1627$.

(18) a) Sugahara, T.; Murakami, K.; Yorimitsu, H.; Osuka, A. Palladium-Catalyzed Amination of Aryl Sulfides with Anilines. Angew. Chem. Int. Ed. 2014, 53, 9329-9333; b) Gao, K.; Yorimitsu, H.; Osuka, A. Palladium-Catalyzed Amination of Aryl Sulfides with Aliphatic Amines. Eur. J. Org. Chem. 2015, 2015, 2678-2682; c) Pratap, R.; Yorimitsu, H. Palladium-Catalyzed Amination of Aryl Sulfides and Sulfoxides with Azaarylamines of Poor Nucleophilicity. Synthesis 2019, 51, 2705-2712.

(19) a) Lian, Z.; Bhawal, B. N.; Yu, P.; Morandi, B. Palladium-Catalyzed Carbon-Sulfur or Carbon-Phosphorus Bond Metathesis by Reversible Arylation. Science 2017, 356, 1059-1063; b) Delcaillau, T.; Bismuto, A.; Lian, Z.; Morandi, B., Nickel-Catalyzed Inter- and Intramolecular Aryl Thioether Metathesis by Reversible Arylation. Angew. Chem. Int. Ed. 2020, 59, 2110-2114.

(20) a) Liebeskind, L. S.; Srogl, J. Thiol Ester-Boronic Acid Coupling. A Mechanistically Unprecedented and General Ketone Synthesis. J. Am. Chem. Soc. 2000, 122, 11260 11261; b) Barbero, N.; Martin, R. Ligand-Free Ni-Catalyzed Reductive Cleavage of Inert Carbon - Sulfur Bonds. Org. Lett. 2012, 14, 796-799; c) Modha, S. G.; Mehta, V. P.; Van Der Eycken, E. V. Transition Metal-Catalyzed C-C Bond Formation via C-S Bond Cleavage: An Overview. Chem. Soc. Rev. 2013, 42, 5042-5055; d) Wang, L.; He, W.; Yu, Z. Transition-Metal Mediated Carbon-Sulfur Bond Activation and 
This document is the Accepted Manuscript version of a Published Work that appeared in final form in ACS Catalysis, copyright (C) American Chemical Society after peer review and technical editing by the publisher. To access the final edited and published work see https://doi.org/10.1021/acscatal.0c00393

Transformations. Chem. Soc. Rev. 2013, 42, 599-621; e) Tobisu, M.; Masuya, Y.; Baba, K.; Chatani, N. Palladium(II)-Catalyzed Synthesis of Dibenzothiophene Derivatives via the Cleavage of Carbon-Sulfur and Carbon-Hydrogen Bonds. Chem. Sci. 2016, 7, 25872591; f) Ma, Y.; Cammarata, J.; Cornella, J. Ni-Catalyzed Reductive Liebeskind-Srog1 Alkylation of Heterocycles. J. Am. Chem. Soc. 2019, 141, 1918-1922.

(21) Muto, K.; Yamaguchi, J.; Lei, A.; Itami, K. Isolation, Structure, and Reactivity of an Arylnickel(II) Pivalate Complex in Catalytic C-H/C-O Biaryl Coupling. J. Am. Chem. Soc. 2013, 135, 16384-16387.

(22) Legnani, L.; Prina-Cerai, G.; Delcaillau, T.; Willems, S.; Morandi, B. Efficient Access to Unprotected Primary Amines by Iron-Catalyzed Aminochlorination of Alkenes. Science 2018, 362, 434-439.

(23) Ge, S.; Hartwig, J. F. Nickel-Catalyzed Asymmetric $\alpha$-Arylation and Heteroarylation of Ketones with Chloroarenes: Effect of Halide on Selectivity, Oxidation State, and RoomTemperature Reactions. J. Am. Chem. Soc. 2011, 133, 16330-16333.

(24) Hills, I. D.; Netherton, M. R.; Fu, G. C. Toward an Improved Understanding of the Unusual Reactivity of $\mathrm{Pd}^{0} /$ Trialkylphosphane Catalysts in Cross-Couplings of Alkyl Electrophiles: Quantifying the Factors That Determine the Rate of Oxidative Addition. Angew. Chem. Int. Ed. 2003, 42, 5749-5752.

(25) a) Cornella, J.; Gómez-Bengoa, E.; Martin, R. Combined Experimental and Theoretical Study on the Reductive Cleavage of Inert C-O Bonds with Silanes: Ruling out a Classical Ni(0)/Ni(II) Catalytic Couple and Evidence for Ni(I) Intermediates. J. Am. 
This document is the Accepted Manuscript version of a Published Work that appeared in final form in ACS Catalysis, copyright (C) American Chemical Society after peer review and technical editing by the publisher. To access the final edited and published work see https://doi.org/10.1021/acscatal.0c00393

Chem. Soc. 2013, 135, 1997-2009; b) Guard, L. M.; Mohadjer Beromi, M.; Brudvig, G. W.; Hazari, N.; Vinyard, D. J. Comparison of Dppf-Supported Nickel Precatalysts for the Suzuki-Miyaura Reaction: The Observation and Activity of Nickel(I). Angew. Chem. Int. Ed. 2015, 54, 13352-13356; c) Desnoyer, A. N.; Love, J. A. Recent Advances Well-Defined, Late Transition Metal Complexes That Make and/or Break CN, C-O and C-S Bonds. Chem. Soc. Rev. 2017, 46, 197-238; d) Diccianni, J. B.; Hu, C. T.; Diao, T. Insertion of CO 2 Mediated by a (Xantphos) $\mathrm{Ni}^{\mathrm{I}}$-Alkyl Species . Angew. Chem. Int. Ed. 2019, 58, 13865-13868. For recent studies on Ni(III) and Ni(IV) complexes see: e) Camasso, N. M.; Canty, A. J.; Ariafard, A.; Sanford, M. S. Experimental and Computational Studies of High-Valent Nickel and Palladium Complexes. Organometallics 2017, 36, 4382-4393; f) Ichiishi, N.; Malapit, C. A.; Woźniak, Ł.; Sanford, M. S. Palladium- and Nickel-Catalyzed Decarbonylative C-S Coupling to Convert Thioesters to Thioethers. Org. Lett. 2018, 20, 44-47; g) Bour, J. R.; Ferguson, D. M.; McClain, E. J.; Kampf, J. W.; Sanford, M. S. Connecting Organometallic Ni(III) and Ni(IV): Reactions of Carbon-Centered Radicals with HighValent Organonickel Complexes. J. Am. Chem. Soc. 2019, 141, 8914-8920.

(26) a) Hartwig, J. F.; Richards, S.; Barañano, D.; Paul, F. Influences on the Relative Rates for C-N Bond-Forming Reductive Elimination and $\beta$-Hydrogen Elimination of Amides. A Case Study on the Origins of Competing Reduction in the Palladium-Catalyzed Amination of Aryl Halides. J. Am. Chem. Soc. 1996, 118, 3626-3633; b) Driver, M. S.; Hartwig, J. F. Carbon-Nitrogen-Bond-Forming Reductive Elimination of Arylamines from Palladium(II) Phosphine Complexes. J. Am. Chem. Soc. 1997, 119, 8232-8245; c) 
This document is the Accepted Manuscript version of a Published Work that appeared in final form in ACS Catalysis, copyright (C) American Chemical Society after peer review and technical editing by the publisher. To access the final edited and published work see https://doi.org/10.1021/acscatal.0c00393

Roy, A. H.; Hartwig, J. F. Directly Observed Reductive Elimination of Aryl Halides from Monomeric Arylpalladium(II) Halide Complexes. J. Am. Chem. Soc. 2003, 125, 13944-13945; d) Roy, A. H.; Hartwig, J. F. Reductive Elimination of Aryl Halides upon Addition of Hindered Alkylphosphines to Dimeric Arylpalladium(II) Halide Complexes. Organometallics 2004, 23, 1533-1541.

(27) a) Koo, K.; Hillhouse, G. L. Indoline Synthesis via Coupling of Phenethyl Grignard Reagents with Organoazides Mediated by (Alkylphosphine)Nickel(II) Complexes. Organometallics 1996, 15, 1994-1996; b) Bour, J. R.; Camasso, N. M.; Meucci, E. A.; Kampf, J. W.; Canty, A. J.; Sanford, M. S. Carbon-Carbon Bond-Forming Reductive Elimination from Isolated Nickel(III) Complexes. J. Am. Chem. Soc. 2016, 138, 1610516111.

(28) Blackmond, D. G. Kinetic Profiling of Catalytic Organic Reactions as a Mechanistic Tool. J. Am. Chem. Soc. 2015, 137, 10852-10866.

(29) Martínez-Carrión, A.; Howlett, M. G.; Alamillo-Ferrer, C.; Clayton, A. D.; Bourne, R. A.; Codina, A.; Vidal-Ferran, A.; Adams, R. W.; Burés, J. Kinetic Treatments for Catalyst Activation and Deactivation Processes Based on Variable Time Normalization Analysis. Angew. Chem. Int. Ed. 2019, 58, 10189-10193.

(30) a) Burés, J. What Is the Order of a Reaction? Top. Catal. 2017, 60, 631-633; b) Burés, J. A Simple Graphical Method to Determine the Order in Catalyst. Angew. Chem. Int. Ed. 2016, 55, 2028-2031; c) Burés, J. Variable Time Normalization Analysis: General 
This document is the Accepted Manuscript version of a Published Work that appeared in final form in ACS Catalysis, copyright (C) American Chemical Society after peer review and technical editing by the publisher. To access the final edited and published work see https://doi.org/10.1021/acscatal.0c00393

Graphical Elucidation of Reaction Orders from Concentration Profiles. Angew. Chem.

Int. Ed. 2016, 55, 16084-16087.

TOC

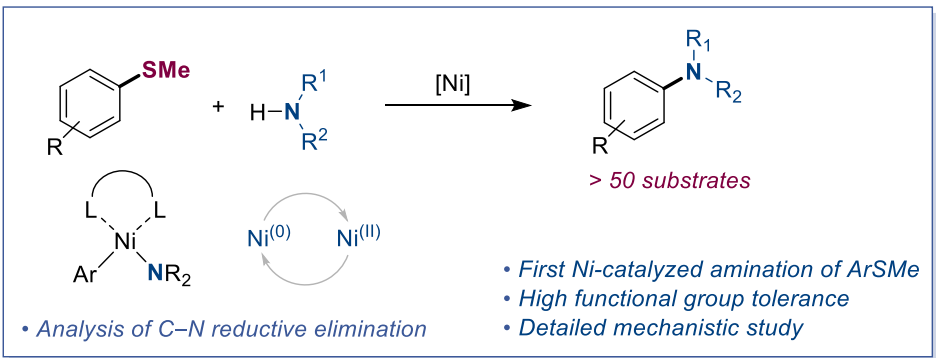

